\title{
Gabriella Lazaridis, International Migration to Europe: From Subjects to Abjects: Migration, Diasporas and Citizenship
}

Palgrave Macmillan, 2015, pp. 199.

In the context of the growing stigmatization of migrants in Europe and other parts of the world, Gabriella Lazaridis' book International Migration to Europe: From Subjects to Abjects, published in 2015 by Palgrave Macmillan, is a very timely contribution to the literature. The book examines processes of inclusion and exclusion of migrants in Europe and is explicitly placed in the context of a discourse which increasingly links migration to security concerns.

With the aim of examining and increasing people's awareness of the exclusion and the "othering" of migrants in Europe, Lazaridis chooses a rights-based approach, theoretically grounded in Arendt's notion of citizenship as the right to have rights. From this starting point, the author develops four different categories of migrant subjectivities, shaped by the migrants' respective legal statuses and representing the inclusion-exclusion continuum: subjects, éjectés, injects, and abjects. In her definition, subjects have access to full citizenship rights, whereas éjectés are of a "quasidocumented status". Injects, having been purposefully "injected" into the receiving country, enjoy a special legal status, and abjects, as irregular migrants, are in the most vulnerable and marginalized situation. Adopting the concept of plastic citizenship as a citizenship which is "fluid, flexible and easily altered by public authorities", Lazaridis emphasizes that states and supranational entities have the power to grant and deprive migrants of their rights, and thereby contribute to a process of abjectification. In addition to the legal status, Lazaridis examines how different forms of "othering" contribute to the marginalization of migrants, attributing special importance to a new form of racism in shaping migrants' situations and subjectivities.

The main argument of the book is that the deprivation of rights contributes to the vulnerability of migrants, but that both states and individual economic and political actors have an interest in maintaining migrants in this partly or fully rightless situation. To construct this argument, in the first chapters of her book Lazaridis analyses the situations of various groups of migrants before turning, in the subsequent chapters, to societal discourses on migration and the incorporation of migrants into society, suggesting a stronger and more inclusive EU citizenship as a possible means to strengthen migrants' rights. In the first chapter, Lazaridis introduces the precarious living situation of undocumented migrants, i.e. the abjects, emphasizing that the circumstance of their irregularity cannot be dissociated from state policies and that "irregularity" and "regularity" constitute a continuum rather than a binary. The second chapter addresses the brain-drain debate over high-skilled migrants coming to Europe and being "injected" into the labour market, but still frequently facing obstacles in fully integrating into it. In the third chapter, Lazaridis introduces migrant entrepreneurship as a means for migrants to improve their living situation, acquire more rights and thereby move from abject to éjecté and potentially subject. 
Nevertheless, the author is clear on the fact that state regulations frequently restrict migrant entrepreneurship. Chapter four analyses the exclusion of migrants in Europe from a gendered perspective: immigration rules being mostly racist and sexist, female migrants face increased vulnerabilities. Another group subject to extreme vulnerabilities are trafficked persons, whose situation is addressed in the fifth chapter. Lazaridis argues that states concentrate mainly on combating traffickers instead of protecting victims, the former policies being in line with their anti-immigrant policies. This links to the subsequent chapter, which discusses the growing securitization of migration discourse. Here, Lazaridis points out how the construction of migrants as a political, economic, and societal threat results in a downward spiral of increased border controls, heightened insecurity of migrants on their journey to Europe, and a growing rejection of migrants in the receiving countries, a process which is economically and politically profitable for certain actors. The penultimate chapter examines how migrants can become part of the receiving society, for example through policies of multiculturalism and regularisation. Lazaridis concludes her discussion on migrant rights by examining whether EU citizenship as a postnational type of citizenship could constitute an alternative form of citizenship, based on residence instead of nationality. Lazaridis observes the emergence of an "unbounded citizenship" via transnational social movements and suggests the adoption of a "transversal perspective" in rethinking citizenship as encompassing multi-layered identities, thereby making it more inclusive.

Having provided an overview of the book, some of its main points are discussed in further detail below: the adoption of a rights-based approach grounded in the categories of abjects, éjectés, injects and subjects; the migration theory underlying Lazaridis' analysis; issues of intersectionality; and the author's depiction of Europe and its responsibility.

The rights-based approach allows Lazaridis to analyse the impact of national and supranational regulations on migrant subjectivities, rather than merely focusing on the migrants' economic situation. A further advantage of the approach is its openness to the integration of factors such as racism and sexism into the equation and to taking into consideration the continuum between "regular" and "irregular" migration, the latter especially further rendered possible by the adoption of the concept of plastic citizenship. Most crucially, the rights-based approach allows her to examine different types of migration outside the usual categories. However, the way in which Lazaridis puts this approach into practice constrains her results. First, the category of injects seems to be very broad, as it encompasses all migrants with a special legal status, thereby including both refugees and high-skilled workers, such as holders of blue cards, whose legal status and living situations can differ significantly. It would be worthwhile to examine whether high-skilled workers and refugees face similar experiences based on their legal status, but the book does not undertake such a comparison, leaving an empty silence regarding the situation of refugees and 
implicitly equating their situation to that of high-skilled workers. This is not only misleading but dangerous, since it risks flattening out existing inequalities.

Second, the above-mentioned potential of these categories to cut across existing categories is not realised. The approach taken by Lazaridis could potentially allow an examination of parallels across the typical categories such as high-skilled workers and refugees, as well as differences and nuances within these groups. Keeping the existing categories somewhat loose and open, instead of merely fitting them into the new categories of abjects, éjectés, injects and subjects, would allow for new results to arise. Third, the category of abjects is misleading in the author's definition of the abject as existing "between the concept of a subject and the concept of an object. The abject is something which used once to be a subject". This assumes that every migrant who she considers to be an abject has formerly been a subject, someone the author describes as "enjoying full citizenship rights". This clearly does not correspond to the reality, in which primarily people who are already in a vulnerable situation before migration risk facing a precarious and rightless situation after migration. In this sense, reversing the subtitle of the book to From Abjects to Subjects would not only be more logical, but also better reflect the content of the book, since Lazaridis suggests several strategies for migrants to gain more rights, such as processes of regularisation, entrepreneurship and citizenship, and thereby possibilities to move from abject to subject.

This also demonstrates that at certain points Lazaridis stresses migrants' agency, while being aware of the power of states, e.g. their capacity to grant rights. In spite of this, in other parts of the book Lazaridis creates an image of migrants as passive playthings of external factors. This impression is especially pronounced in the chapter on skilled migration to Europe, which in fact mainly addresses the issue of brain drain. The situation of individual high-skilled migrants in Europe and their own interests of migration are only marginally discussed. In general, the main underlying migration theory, even though not explicitly named, is the push-pull-model, which has been highly criticized for neglecting the agency of the individual and is therefore not very compatible with Lazaridis' claim of wanting to highlight the agency of the migrants.

A more systematic account is given of intersectionality, predominantly focusing on gender and race, but also taking into consideration other factors such as skills, age and religion. All of these are introduced as determining dimensions in the process of "othering". Even though it needs to be acknowledged that Lazaridis repeatedly emphasizes the agency of migrant women and rejects their general portrayal as victims, one might ask whether she does not contribute to such a portrayal herself, since when she focuses explicitly on women, they are either depicted as maids, sex workers or similar. In spite of the fact that Lazaridis gives a nuanced picture of the gender dimension within these areas, a larger acknowledgement that women also figure within other forms of migration would be much appreciated to effectively move away from a stereotypical portrayal of women in general, and migrant women in particular. Lazaridis addresses "new racism" as a factor which crucially shapes 
migrants' situations. This concept describes racism as based on ideas of cultural and national, rather than previous notions of biological, superiority. On the one hand, this concept is useful for grasping "hidden racism", but on the other, one needs to remain sensitive to the fact that the supposedly "old" forms of racism persist and that racism is not directed towards different groups to the same extent, as the above definition might lead one to assume.

A further point to be addressed in this regard is that the migration to Europe covered by Lazaridis' analysis is predominantly migration originating in the Global South. This leaves out a significant number of people migrating to Europe from the Global North. Including these migrants more thoroughly into the equation might show more clearly in how far the region of origin influences migrants' situations and give further insights into how racism shapes migrant subjectivities. In general, Lazaridis portrays migration to Europe as a struggle which includes economic, political, legal, and social dimensions. However, not all migrants might face these challenges, which is something that should not be neglected in a book on international migration to Europe.

One of the major strengths of Lazaridis' book is the nuanced depiction of Europe's role in shaping migrant subjectivities. Lazaridis shows that Europe holds a clear responsibility for the precarious situation of migrants, by repeatedly pointing out the existence of a strong European demand for cheap labour, and therefore for irregular, and potentially trafficked, migrants. She is explicit in showing that the situation of migrants is largely influenced by states' (anti-)immigration policies and clearly points out the paradox of Europe seemingly standing up for human rights while at the same time restricting immigration. While focusing on Europe's responsibility, Lazaridis is careful to give equal consideration to the agency of the sending countries, e.g. their role in encouraging or discouraging migration or in contributing to the shaping of female migrants' struggles. Another aspect that should also be positively noted in this respect is that in spite of the fact that the book's focus is on migration to Europe, Lazaridis finds space to integrate the creation of "Others" within Europe, using the example of the Roma as a European minority who also de facto do not enjoy full citizenship. Significantly, Lazaridis succeeds in distinguishing between the national and the EU level. This is not only apparent in the fact that she uses examples taken from various national contexts, while also discussing EU regulations, but mainly in her problematizing of the EU's structural constitution as an entity composed of sovereign nation-states. This theme cuts across her analysis of migrant subjectivities in Europe, the national dominance within the EU repeatedly being portrayed as a major obstacle to migrants' gaining access to rights. This culminates in her discussion of EU citizenship, in which Lazaridis shows that the EU as a supranational body is also willing to move towards a stronger EU citizenship, detached from the national one, but is hampered not only by its own economic considerations but above all by the nation-state make-up of the EU. 
International Migration to Europe: From Subjects to Abjects shows to what extent national and supranational regulations as well as societal processes contribute to creating migrant subjectivities and constructing migrants as the "Other", who is diachronically juxtaposed to the "Self". In this well-researched book, Lazaridis not only presents an engaged discussion about the construction of migrant subjectivities at the current stage, but also places them in historical context and points to the future by proposing alternatives, most notably in the form of a postnational EU citizenship.

Laura Boucsein 